\title{
Estudo dos dados obtidos com a cirurgia para confecção de prega palpebral em pacientes orientais
}

\author{
Study of the data obtained on surgery to make an \\ eyelid fold in oriental patients
}

\author{
Gisele Scholte de Souza Vieira ${ }^{1}$ \\ Eurípedes da Mota Moura² \\ Alfred Van Baak ${ }^{3}$
}

Trabalho realizado no Hospital do Servidor Público Estadual - SP e na Clínica particular da Dra. Gisele Scholte Vieira.

${ }^{1}$ Médica oftalmologista.

2 Professor Doutor pelo Hospital das Clínicas da Faculdade de Medicina da Universidade de São Paulo - USP - São Paulo (SP) - Brasil.

${ }^{3}$ Médico Assistente do Hospital do Servidor Público Estadual - HSPE - São Paulo (SP) - Brasil.

Endereço para correspondência: Gisele Scholte de Souza Vieira. Avenida Nova Independência, 722 - São Paulo (SP) CEP 04570-001

E-mail: gisele.scholte@terra.com.br

Recebido para publicação em 25.09.2007 Aprovação em 25.03.2008

\begin{tabular}{l}
\hline RESUMO \\
\hline Objetivos: Descrever uma técnica cirúrgica utilizada em grupo de pa- \\
cientes orientais para formar uma prega na pálpebra superior, associada \\
ou não à cirurgia de blefaroplastia, e rever os principais fatores para se \\
atingir um resultado estético satisfatório. Métodos: Foi feito estudo \\
retrospectivo de 12 prontuários de pacientes submetidos à cirurgia para \\
a confecção de uma prega palpebral durante o período de abril/2004 a \\
abril/2007. A técnica cirúrgica consistiu na remoção do excesso de pele \\
e gordura retro-septal quando presentes, e colocação de suturas cutâneas \\
ao nível do epitarso para formar uma prega palpebral. Uma segunda \\
cirurgia foi feita em dois pacientes para melhora na simetria da prega \\
palpebral. Resultados: Todos os pacientes demonstraram satisfação \\
com o resultado final, notando-se pálpebras simétricas e com aspecto \\
natural. Conclusão: A técnica cirúrgica utilizada neste grupo de pacien- \\
tes para formação de prega palpebral apresentou resultados estéticos \\
bons em todos os casos.
\end{tabular}

Descritores: Blefaroplastia/métodos; Pálpebras/cirurgia; Grupo com ancestrais do continente asiático; Cirurgia plástica/métodos; Japão/etnologia

\section{INTRODUÇÃO}

As denominações usadas popularmente para a pálpebra oriental (ou asiática) são "pálpebra dupla", quando há presença de prega semelhante à pálpebra ocidental, e "pálpebra simples" na ausência de prega ${ }^{(1)}$. Ambos os tipos de pálpebras estão presentes em aproximadamente metade dos orientais ${ }^{(2)}$.

A cirurgia estética para a confecção da prega palpebral é muito popular nos países asiáticos ${ }^{(2)}$, e pode ser feita em duas situações: isolada ou associada à blefaroplastia superior. Também pode ser denominada "blefaroplastia para jovens asiáticos" quando isolada ${ }^{(3)}$.

A blefaroplastia superior é uma cirurgia que consiste na remoção do excesso de tecidos que se nota na pálpebra em maior ou menor grau. $\mathrm{O}$ excesso de pele na pálpebra superior ou dermatocalase, pode causar desde problemas estéticos até mesmo funcionais, quando o paciente não consegue abrir bem os olhos ou há perda de parte do campo visual superior. Freqüentemente os pacientes se queixam de peso nas pálpebras e cansaço visual. No exame préoperatório, avalia-se a quantidade de pele, músculo orbicular e gordura retroseptal a serem removidos ${ }^{(4)}$.

Quando a cirurgia é realizada em pacientes asiáticos, outros fatores importantes devem ser analisados pelas diferenças anatômicas que podem ser encontradas nestas pálpebras: ausência de prega palpebral e presença de epicanto $^{(1)}$. 
As primeiras descrições de cirurgias para a confecção de sulcos palpebrais em pacientes orientais (ou "ocidentalização") data do final do século XIX ${ }^{(5)}$. Desde então várias técnicas cirúrgicas foram apresentadas, podendo ser divididas em dois tipos: as que utilizam incisões cirúrgicas ${ }^{(2-3,6)}$ e a técnica de colocação de sutura, sem incisão da pele ${ }^{(7-8)}$.

Atualmente a cirurgia para a formação de uma prega palpebral é o procedimento estético mais realizado entre os orientais $^{(2,9)}$.

O objetivo deste trabalho é analisar os resultados obtidos com uma técnica para a formação de prega palpebral, associada ou não à cirurgia de blefaroplastia superior.

\section{MÉTODOS}

No período de abril de 2004 a abril de 2007, 12 pacientes orientais foram submetidos à cirurgia na pálpebra superior, sendo que metade das cirurgias foram realizadas no Hospital do Servidor Público Estadual - SP e os demais 6 pacientes em uma clínica particular. Dentre eles 9 pacientes eram mulheres e três eram homens (Grupo Total). A idade variou entre 25 e 66 anos. No pré-operatório, 8 pacientes ( 7 mulheres e um homem) com idades entre 50 e 66 anos (Grupo 1), tinham como queixa principal o excesso de pele e de bolsas de gordura. Nos demais (Grupo 2), o objetivo com a cirurgia era a formação de uma prega palpebral.

Uma paciente do Grupo 2 relatava uma história de blefaroplastia prévia com formação de prega palpebral, porém com resultado insatisfatório. Os outros três pacientes eram os mais jovens do Grupo Total, com idades de 25 anos (dois homens) e 40 anos (mulher).

Um paciente do Grupo 2 apresentava no pré-operatório uma assimetria que consistia na presença de prega em uma das pálpebras e ausência da mesma na pálpebra contralateral. Sendo assim, apenas o lado sem prega foi operado. Foram realizados exames oftalmológicos completos e avaliações clínicas em todos os pacientes antes da cirurgia.

\section{Técnica cirúrgica}

Todos os pacientes foram submetidos à cirurgia sob anestesia local com sedação.

Após a assepsia da face e com os pacientes de olhos fechados, a pele da pálpebra superior foi demarcada com uma caneta de ponta fina. Desenhou-se uma linha entre 4 e $6 \mathrm{~mm}$ a partir da margem palpebral, no local da futura prega, tendo como limite medial o ponto lacrimal e o limite lateral a comissura externa ou um ponto 10 a $15 \mathrm{~mm}$ além desta. Quando já se notava um esboço de prega aproveitava-se esta altura para a marcação da linha. $\mathrm{O}$ excesso de pele, quando presente, foi calculado através de uma pinça sem dentes e a linha superior demarcada. Com isso, a altura da prega palpebral a ser formada e o excesso de pele a ser retirado foi definido. A pálpebra contralateral também foi marcada de maneira idêntica, com exceção do paciente do Grupo 2 em que a cirurgia foi unilateral.
O anestésico utilizado foi Xilocaína ${ }^{\circledR}$ a $2 \%$ com vasoconstrictor (adrenalina na concentração de 1:200.000) injetado no tecido subcutâneo. Para a incisão cutânea utilizou-se uma lâmina de bisturi número 15. Com o auxílio de uma pinça e uma tesoura, foi feita a remoção da pele em excesso juntamente com músculo orbicular pré-septal. Nos pacientes do Grupo 2, apenas uma elipse de aproximadamente $2 \mathrm{~mm}$ de pele foi removida. No paciente em que foi feita a cirurgia só em uma pálpebra, nada foi retirado de pele. Na presença de bolsas de gordura, o septo orbitário era aberto e a gordura removida. Com o auxílio do cautério bipolar era feita uma hemostasia cuidadosa.

Para a confecção da prega palpebral, o plano orbicular próximo à incisão inferior era aberto em toda a extensão da pálpebra e, através de uma dissecção profunda, atingíamos o plano do epitarso. Pontos de sutura utilizando-se o fio seda 6.0 foram colocados passando pela pele em seu limite inferior, pelo epitarso e saindo novamente na pele em seu limite superior. Aproximadamente 5 a 6 pontos foram colocados desta maneira, distribuídos uniformemente pela pálpebra (Figura 1). Na pálpebra contralateral a profundidade na colocação da sutura era rigorosamente a mesma para uma adequada simetria.

No pós-operatório, os pacientes fizeram uso de pomadas oftálmicas com antibiótico e compressas frias. Os pontos de sutura foram retirados após uma semana.

\section{RESULTADOS}

A média do tempo de observação pós-operatória foi de 18 meses.

Do total de pacientes, 10 obtiveram um resultado estético satisfatório no pós-operatório com pregas palpebrais simétricas. Entretanto, duas pacientes do Grupo 1 necessitaram de uma segunda cirurgia por apresentarem assimetria na profundidade do sulco palpebral. Em uma das pacientes foi feita uma correção cirúrgica após uma semana da primeira cirurgia; este

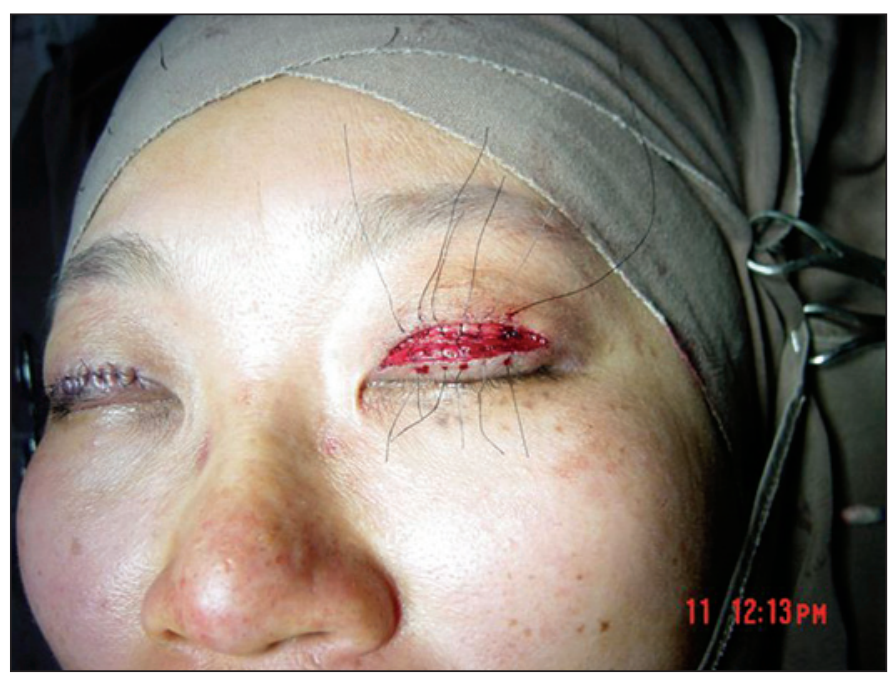

Figura 1 - Passagem dos fios 
procedimento não necessitou de nova injeção de anestésico e foram colocados novos pontos de sutura mais profundos na pálpebra em que a prega aparecia mais discreta. $\mathrm{O}$ resultado final foi satisfatório (Figuras 2 e 3). Em outra paciente, o segundo procedimento foi feito 6 meses após a primeira cirurgia. Uma das pregas formadas apresentava-se mais profunda do que na pálpebra contralateral. Como a paciente estava mais satisfeita com a prega menos profunda, a cirurgia consistiu em uma incisão cutânea na altura da prega mais profunda e liberação dos tecidos até o plano epitarsal. Novos pontos de sutura foram colocados mais superficialmente do que os anteriores. A paciente ficou satisfeita com o resultado final.

Não houve nenhum caso de infecção, hemorragia e/ou formação de cicatriz hipertrófica.

\section{DISCUSSÃO}

Para que tenhamos bons resultados ao realizarmos a cirurgia de blefaroplastia superior em pacientes asiáticos, ou a cirurgia para formação de prega palpebral ("ocidentalização"), temos que conhecer bem a anatomia da pálpebra oriental ${ }^{(10-12)}$.

Anatomicamente, a presença da prega palpebral se deve a uma parte das fibras da aponeurose do músculo levantador que se dirigem à pele; nas pálpebras sem prega estas fibras estão ausentes ${ }^{(13)}$. Além disso, na pálpebra oriental, a aponeurose do levantador se une ao septo orbitário em uma altura abaixo da borda superior do tarso, o que situa a gordura préaponeurótica mais próxima à margem palpebral, diferentemente da pálpebra ocidental em que a fusão da aponeurose com o septo ocorre poucos milímetros acima da borda tarsal; é freqüente a presença de gordura submuscular se estendendo inferiormente até a base do tarso superior ${ }^{(1)}$.

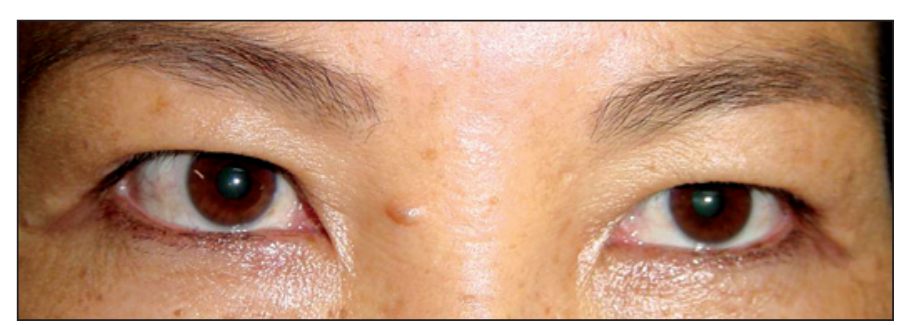

Figura 2 - Pré-operatório

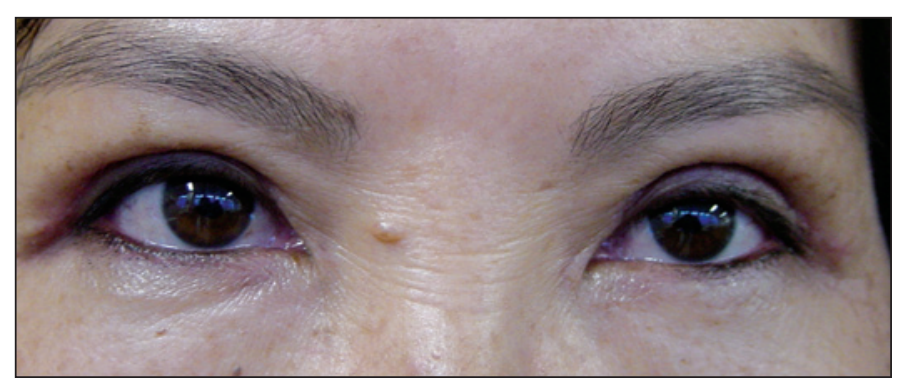

Figura 3 - Pós-operatório
Outro fator importante ao realizarmos cirurgia estética envolvendo pálpebras superiores em pacientes orientais é sabermos o que o paciente espera como resultado final. É desejável a formação de uma prega palpebral? Em que altura esta prega estará localizada?

No grupo de pacientes desta amostra, todos demonstraram a vontade da criação de uma prega palpebral, mesmo aqueles para os quais o objetivo principal seria a remoção do excesso de pele e de bolsas de gordura.

Quando a presença de prega palpebral é desejada pelo paciente, ela deve ser formada de modo que seja duradoura e tenha um aspecto natural e simétrico ${ }^{(14)}$. Para a localização da futura prega palpebral é importante uma análise pré-operatória cuidadosa. A marcação da pele deve ser feita de uma forma precisa, sempre com o uso de compasso, para não excedermos a altura ideal que seria 4 a $6 \mathrm{~mm}$ a partir da margem palpebral. Os dois lados devem ser marcados ao mesmo tempo, antes do início da cirurgia. Além disso, não se deve criar uma prega em um novo local quando já existe um esboço de prega.

Os dois motivos principais de insatisfação pelos pacientes quanto ao resultado final no pós-operatório são a assimetria na profundidade dos sulcos formados e a altura alta da prega palpebral $^{(2)}$. Uma alta taxa de complicações é constatada por alguns autores, entre elas retração palpebral, blefaroptose e depressão supratarsal(15-16).

Como regra geral, na presença de prega epicantal, esta não deve ser removida pois normalmente não incomoda o paciente e a pálpebra oriental têm maior tendência à formação de cicatriz hipertrófica ${ }^{(1)}$.

\section{CONCLUSÃO}

A técnica utilizada neste grupo de pacientes mostrou-se satisfatória quanto ao aspecto natural das pregas palpebrais formadas. Quanto à simetria, em apenas dois casos foi necessária uma reintervenção cirúrgica, com bom resultado final.

Concluímos ser uma técnica duradoura, visto que não houve alteração no pós-operatório mais tardio em relação à profundidade da prega formada em nenhum dos nossos casos.

\section{ABSTRACT}

Purposes: To describe a surgical technique utilized in a group of Oriental patients to create a crease in the superior eyelid, associated or not with a blepharoplasty, and to review the main factors to attain a satisfactory final result. Methods: A retrospective study was made in 12 data of patients submitted to a surgery for creation of an eyelid crease during the period of April/2004 to April/2007. The surgical technique consisted of the removal of excess skin and retroseptal fat when present, and the placement of cutaneous sutures on the epitarsus to form an eyelid crease. A second surgery was done in two pa- 
tients to improve the symmetry of the eyelid crease. Results: All patients demonstrated satisfaction with the final result, symmetrical eyelids and natural look being observed. Conclusion: The surgical technique utilized in this group of patients for the formation of an eyelid crease showed good esthetical results in all cases.

Keywords: Blepharoplasty/methods; Eyelids/surgery; Asian continental ancestry group; Surgery plastic/methods; Japan/ ethnology

\section{REFERÊNCIAS}

1. Tse DT, editor. Color atlas of ophthalmic surgery: oculoplastic surgery. Philadelphia: J.B. Lippincott; 1992.

2. Kim YW, Park HJ, Kim S. Secondary correction of unsatisfactory blepharoplasty: removing multilaminated septal structures and grafting of preaponeurotic fat. Plast Reconstr Surg. 2000;106(6):1399-404; discussion 1405-6.

3. Yoon KC, Park S. Systematic approach and selective tissue removal in blepharoplasty for young Asians. Plast Reconstr Surg. 1998;102(2):502-8.

4. Soares EJ, Moura EM, Gonçalves JO. Cirurgia plástica ocular. São Paulo: Roca; 1997.
5. Mikamo K. A technique in the double eyelid operation. J Chugaishinpo. 1896; 396:9.

6. Kang DH, Choi JH, Koo SH, Park SH. Laser blepharoplasty in Asians. Ann Plast Surg. 2002;48(3):246-51.

7. Aki FE, Sakae EK, Baracat GH. Construção do sulco palpebral superior em pacientes orientais sem incisão cirúrgica: experiência em 13 anos. Arq Bras Oftalmol. 2003;66(3):325-31.

8. Liu D. Oriental blepharoplasty. Plast Reconstr Surg. 1989;84(4):698-9. Comment on: Plast Reconstr Surg. 1989;83(2):236-42.

9. Chen WP. Concept of triangular, trapezoidal, and rectangular debulking of eyelid tissues: application in Asian blepharoplasty. Plast Reconstr Surg. 1996; 97(1):212-8.

10. Kikkawa DO, Kim JW. Asian blepharoplasty. Int Ophthalmol Clin. 1997; 37(3):193-204.

11. Watanabe K. Measurement method of upper blepharoplasty for Orientals. Aesthetic Plast Surg. 1993;17(1):1-8.

11. Doxanas MT, Serra F. Surgical revision of oriental eyelids. Ophthalmic Surg. 1985;16(10):657-9.

12. Morikawa K, Yamamoto H, Uchinuma E, Yamashina S. Scanning electron microscopic study on double and single eyelids in Orientals. Aesthetic Plast Surg. 2001;25(1):20-4.

13. Kang DH, Koo SH, Choi JH, Park SH. Laser blepharoplasty for making double eyelids in Asians. Plast Reconstr Surg. 2001;107(7):1884-9.

14. Weng CJ, Noordhoff MS. Complications of Oriental blepharoplasty. Plast Reconstr Surg. 1989;83(4):622-8.

15.Chen WP. Asian blepharoplasty. Update on anatomy and techniques. Ophthal Plast Reconstr Surg. 1987;3(3):135-40.

\title{
$44^{\circ}$ Congresso do Centro de Estudos Oftalmológicos "Cyro de Rezende"
}

\author{
31 de outubro \\ a $1^{\circ}$ de novembro de 2008 \\ Ribeirão Preto - SP
}

INFORMAÇÕES

E-mail: amelia@fmrp.usp.br 